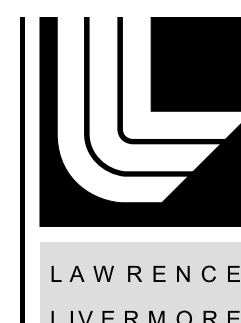

LAW REN CE LIVERMORE NATIO N A L LABORATORY

\section{RF PLASMA SOURCE FOR A HEAVY ION FUSION INJECTOR}

G. A. Westenskow, D. P. Grote, E. Halaxi, J. W. Kwan, W. L. Waldron

June 29, 2004

Heavy Ion Fusion Symposium

Princeton, NJ, United States

June 7, 2004 through June 11, 2004 
This document was prepared as an account of work sponsored by an agency of the United States Government. Neither the United States Government nor the University of California nor any of their employees, makes any warranty, express or implied, or assumes any legal liability or responsibility for the accuracy, completeness, or usefulness of any information, apparatus, product, or process disclosed, or represents that its use would not infringe privately owned rights. Reference herein to any specific commercial product, process, or service by trade name, trademark, manufacturer, or otherwise, does not necessarily constitute or imply its endorsement, recommendation, or favoring by the United States Government or the University of California. The views and opinions of authors expressed herein do not necessarily state or reflect those of the United States Government or the University of California, and shall not be used for advertising or product endorsement purposes. 
TH.P-12

\title{
RF PLASMA SOURCE FOR A HEAVY ION FUSION INJECTOR *
}

\author{
G.A. Westenskow, D.P Grote, E. Halaxa, Lawrence Livermore National Laboratory \\ J.W Kwan, W.L Waldron, Lawrence Berkeley National Laboratory
}

\begin{abstract}
We are developing high-current ion sources for Heavy Ion Fusion applications. Our proposed RF plasma source starts with an array of high current density mini-beamlets (of a few mA each at 100 $\mathrm{mA} / \mathrm{cm}^{2}$ ) that are kept separated from each other within a set of acceleration grids. After they have gained sufficient kinetic energy $(>1.2 \mathrm{MeV})$, the mini-beamlets are allowed to merge together to form a high current beam (about $0.5 \mathrm{~A}$ ) with low emittance. Simulations have been done to maximize the beam brightness within the physical constraints of the source.

We have performed a series of experiments on an RF plasma source. A 80-kV 20- $\mu$ s source has produced up to $5 \mathrm{~mA}$ of $\mathrm{Ar}^{+}$in a single beamlet and we measured the emittance of a beamlet, its energy spread, and the fraction of ions in higher charge states. We have also tested a 50-kV 61-hole multibeamlet array. Two upcoming experiments are being prepared: the first experiment will test full-gradient extraction and transport of 61 beamlets though the first four electrodes, and the second experiment will converge 119 beamlets into an ESQ channel at one-quarter scaled voltage of a 1.6 MV HIF injector.
\end{abstract}

TH.P-12;

PAC codes: (07.77.Ka Charged-particle beam sources and detectors)( 41.85.Ar Beam extraction, beam injection)(29.27.Ac Beam injection and extraction)

Keywords: Ion Source, Particle Injector, Heavy Ion Fusion

Glen Westenskow; LLNL, L-645; PO Box 808, Livermore, CA 94551 , westenskow1@llnl.gov 


\section{BACKGROUND ON RF PLASMA SOURCE}

Following a proposal that the usual limits on brightness for compact ion-beam sources used in Heavy Ion Fusion can be circumvented by using a multi-beamlet injector 1 we have started an experimental program to examine practical issues. The final source envisioned (see Fig. 1) will start with 200 5-mA beamlets across a 100-kV gap. The beamlets will be focused by Einzel Lens while their energy is increased to about $1.2 \mathrm{MeV}$. The beamlets are then merged to produce a 1-A beam with a normalized $4 *$ rms emittance of $1 \pi$-mm-mrad at $1.6 \mathrm{MeV}$.

Beyond providing a low-temperature source that can provide ion emission densities of 100 $\mathrm{mA} / \mathrm{cm}^{2}$, the main physics issues involved in the multi-beamlet approach are emittance growth and envelope matching in the merging process. Computer simulations show that if the initial emittance of the beamlets is small, then it only contributes weakly to the final emittance of the merged beam [1].

\section{STUDYING INDIVIDUAL BEAMLETS}

We are using an rf plasma source to produce an argon ion beam. The plasma chamber has 26-cm inner diameter with multicusp permanent magnets to confine plasma (see Figure 2) . RF power (13 $\mathrm{MHz}$ ) is applied to the source via a 2-turn, 11-cm diameter antenna inside the chamber for producing beam pulses of $20 \mu$ s at up to $10 \mathrm{~Hz}$. We have shown that we can extract $100 \mathrm{~mA} / \mathrm{cm}^{2}$ from the chamber (see Fig. 3). Optimum performance at $80 \mathrm{kV}$ was achieved with 2 mTorr gas in the plasma chamber using $22 \mathrm{~kW}$ of rf drive power The lowest emittance (optics) was achieved when the beamlet current was slightly below the peak current value. We believe that the "roll-over" in Fig. 3 occurred when ions were lost during transport. Increasing the source pressure above 2 mTorr continued to increase the ion density in the chamber, but did not yield higher extracted currents from the gap. Increasing the source pressure also increases the charge exchange in the gap. Current density was found to increase with RF 
power as long as there was sufficient extraction voltage. At $80 \mathrm{kV}$, we have reached our goal of producing $100 \mathrm{~mA} / \mathrm{cm}^{2}$ of $\mathrm{Ar}^{+}$ions (i.e. $4.9 \mathrm{~mA}$ per beamlet). For operation with $10 \mathrm{~kW}$ of drive powers we estimated that less than $5 \%$ of the extracted ions were in the $\mathrm{Ar}^{++}$state.

We used a narrow slit and a slit cup to examine the $x$ - x' phase space of a beamlet. An example is shown in Fig. 4. The normalized emittance for the beamlet was about $0.02 \pi \cdot \mathrm{mm} \cdot \mathrm{mrad}$. The emittance is minimized when the source current density matched the space charge limit. At the optimum condition, the normalized emittance (measured by a double-slit scanner) of $0.0186 \pi$-mm-mrad has an equivalent ion temperature of about $2.0 \mathrm{eV}$.

An early concern was that collisions between the extracted ions and the background gas would yield an excessive amount of charge exchange. The newly created ions would leave the gap with lower energies and different transverse motion. At a 2-mTorr source pressure, the amount of this component is less than $0.3 \%$ of the full energy component, and was spread over a range of $2 \mathrm{keV}$ below the full energy [2]. Additional details about the rf plasma source have been published [2,3].

\section{MULTI-BEAMLET EXPERIMENTS}

We have tested a 61-beamlet extraction array using a series of Einzel lens. The source apertures were $2.2 \mathrm{~mm}$ in diameter and all other electrodes had $4.0 \mathrm{~mm}$ diameter holes. One of our goals was to test the high gradient insulators which were used to assemble the electrode plates. At $50 \mathrm{kV}$ across the $1.6 \mathrm{~cm}$ extraction gap they would occasionally flash over, but usually recondition rapidly. Individually they would hold $80 \mathrm{kV}$ DC potential without beam. A conservative working voltage is about $40 \mathrm{kV} / \mathrm{cm}$ for a $20-\mu$ sec pulse in the gap environment. Seperation between other plates was about $1 \mathrm{~cm}$. 
We tested the the setup show in Figure 5 to about $50 \mathrm{kV}$. Charactization of the merging beamlets was not be done at this stage.

\section{FULL GRADIENT EXPERIMENT}

The Full-Gradient Experiment (see Fig. 6) was designed to test the limit of high current density extraction in the working environment of the RF Plasma source. The dimensions and electric fields are typical of what we would like to use in a driver scale injector. Since we are limited to about $400-\mathrm{kV}$ of pulsed voltage, only the first 5 gaps of a full system can be tested. To reduce the cost we did not used curved plates here.

There is gas streaming through the extraction holes at beam time. The gas pressure in the plasma chamber is about 2 mTorr at beam time. The gas is introduced into the chamber about 100 msec before beam time. As the number of beamlets increases there will be less differential pumping between the chamber and the lens. The voltage pulse length (>90\% level) is $17 \mu$ sec in duration. There will be some beam spill on the plates from the halo particle.

The highest vacuum electric field gradient occurs between the 336-kV plate and the 208-kV plate (shown in Fig. 6), and is $100 \mathrm{kV} / \mathrm{cm}$ on axis. This gap is $1.2 \mathrm{~cm}$. Fields at the edge of the holes are expected to be about $120 \mathrm{kV} / \mathrm{cm}$ for this gap. The gradient along the insulators is $30 \mathrm{kV} / \mathrm{cm}$. The insulators between cups are either $4.27 \mathrm{~cm}$ or $2.13 \mathrm{~cm}$. We have used HGI at up to $50 \mathrm{kV} / \mathrm{cm}$. Achieving these gradients is expected to require conditioning of the surfaces. There are 5 -k $\Omega$ resistors between the column voltage tapoffs and the plates to limit energy that would be dumped into an electrical arc if it occurs between the plates.

The current per beamlet is $3.8 \mathrm{~mA}$ at an extraction current density of $100 \mathrm{~mA} / \mathrm{cm}^{2}$. There are 61 beamlets for a total current of $232 \mathrm{~mA}$. The beamlets will start to merge at about $20 \mathrm{~cm}$ after the exit of 
the last plate. We plan to measure the total current, and acquire images of the beamlets.. Note that the field direction in the forth gap is reversed to produce Einzel lens effect for focusing the beamlets.

\section{MERGING BEAMLETS INTO AN ESQ}

For a proof-of-principle test of the merging process we have designed an experiment at full dimensions, but which will operate at one-quarter the voltage of a drive scaled injector. Since all the voltages in this electrostatic system are reduced by the same factor, and the current density is scaled according to the “3/2” space charge limited condition, the beam optics of merging remains unchanged. A layout is shown in Fig. 7. The concept of converging beamlets into an ESQ is presented elsewhere in these proceedings[2]. There is an extraction plate and 10 lens plates in the experiment. Figure 8 shows a typical curved plate in the lens assembly with 119 apertures. Because the voltages between plates is reduced by factor of four, we did not design reentrant cups, as in the Full-Gradient Experiment (see Fig. 6), to hold the lens. We can use HGI directly between the plates to hold the assemble together.

The emittance growth (normalized to a constant beam current) is minimized when the beamlet energy is high (at the time of merging), the number of beamlets is large, and the beamlets are close to each others. The final emittance depends on the initial beamlet convergent angle and weakly on the ion temperature[1]. Figure 9 shows the evolution of beamlets in configuration space. The $\mathrm{x}$ and $\mathrm{y}$ rms emittance was found to initially rise to different values because of the elliptical shape but later came to an equilibrium value (average between $\mathrm{x}$ and $\mathrm{y}$ emittance) in about $10 \mathrm{~m}$ distance

\section{ACKNOWLEGEMENT}

We would like to thank Gary Freeze, Robert Hall, and Jon Kapica for their assistance with the experiments. 


\section{REFERENCES}

[1] D.P. Grote, E. Henestroza, J.W. Kwan, PRST Accelerators and Beams 6, 014202 (2003).

[2] J.W. Kwan, et al., "Ion Source and Injector Experiments at the HIF/VNL" in these proceedings.

[3.] G.A. Westenskow, et al., "High Current Ion Source Development for Heavy Ion Fusion”, Proceedings of The Third International Conference on Inertial Fusion Sciences and Applications (IFSA2003), Monterey, California, September 7-12, 2003, p. 703.

*This work has been performed under the auspices of the US DOE by UC-LBNL under contract DEAC03-76SF00098 and by UC-LLNL under contract W-7405-ENG-48, for the Heavy Ion Fusion Virtual National Laboratory. 


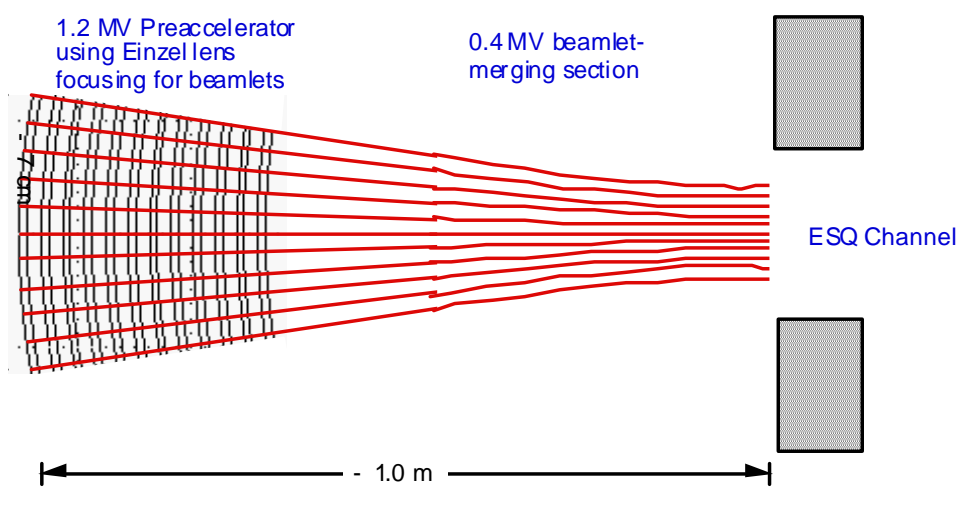

Fig. 1. Layout for the full injector using merging.

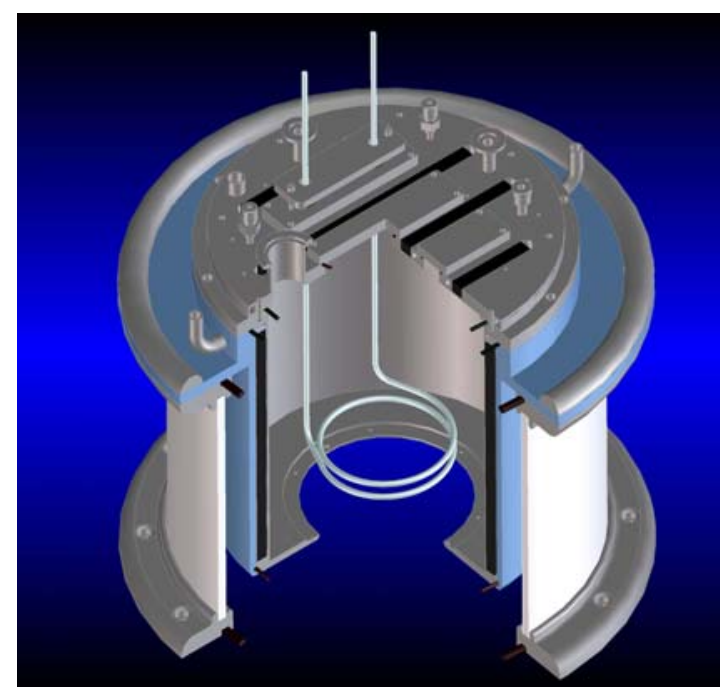

Fig. 2. RF multicusp ion source. 


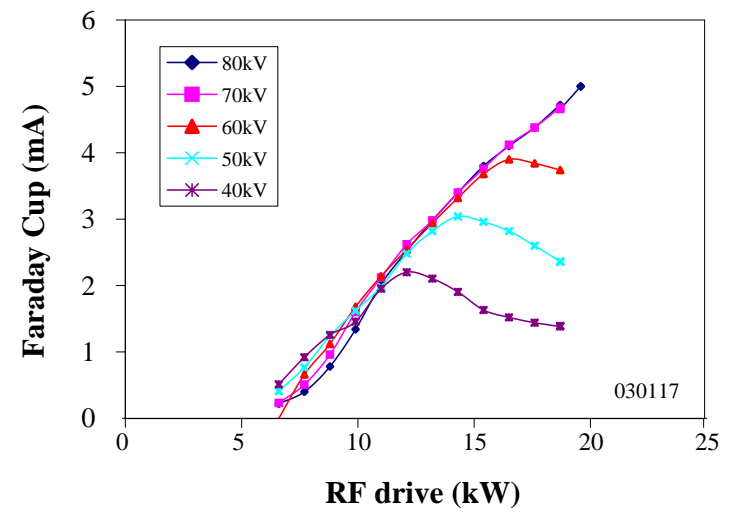

Fig. 3. Current detected at the Faraday Cup for a single beamlet at 2-mTorr source pressure. The source aperture was $2.5 \mathrm{~mm}$ diameter. The curves are at different extraction-gap potentials.

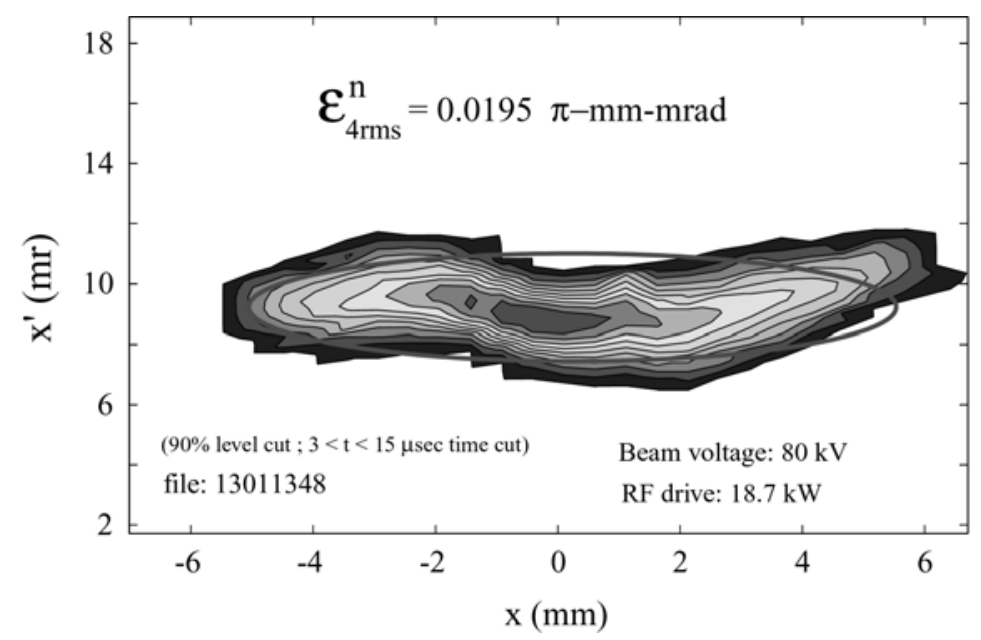

Fig. 4. Transformed phase space of the beamlet shown in the previous figure. 


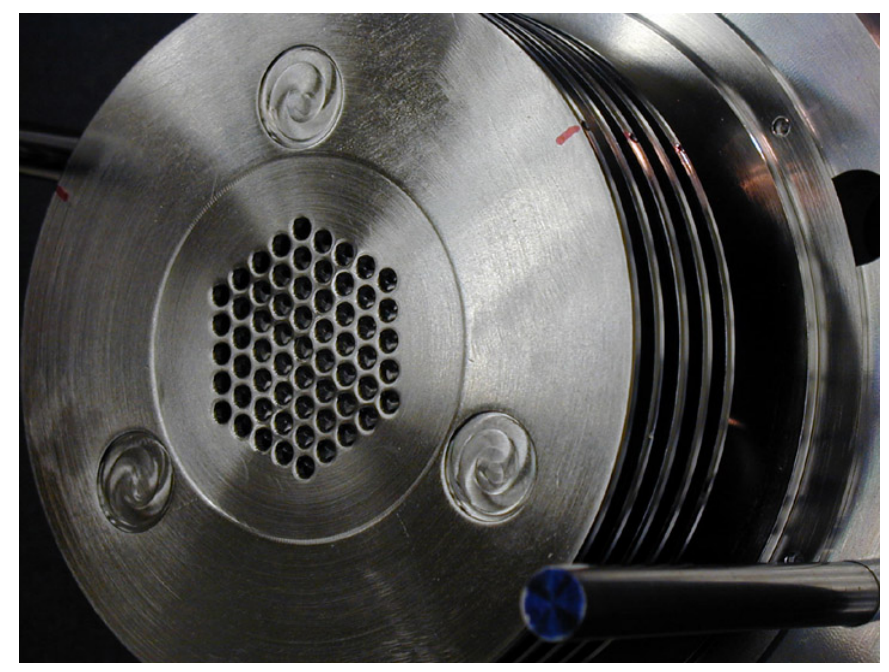

Fig. 5 Einzel Lens installed on the 61 hole extraction array. The distance between top and bottom beamlet hole is $5.2 \mathrm{~mm}$.

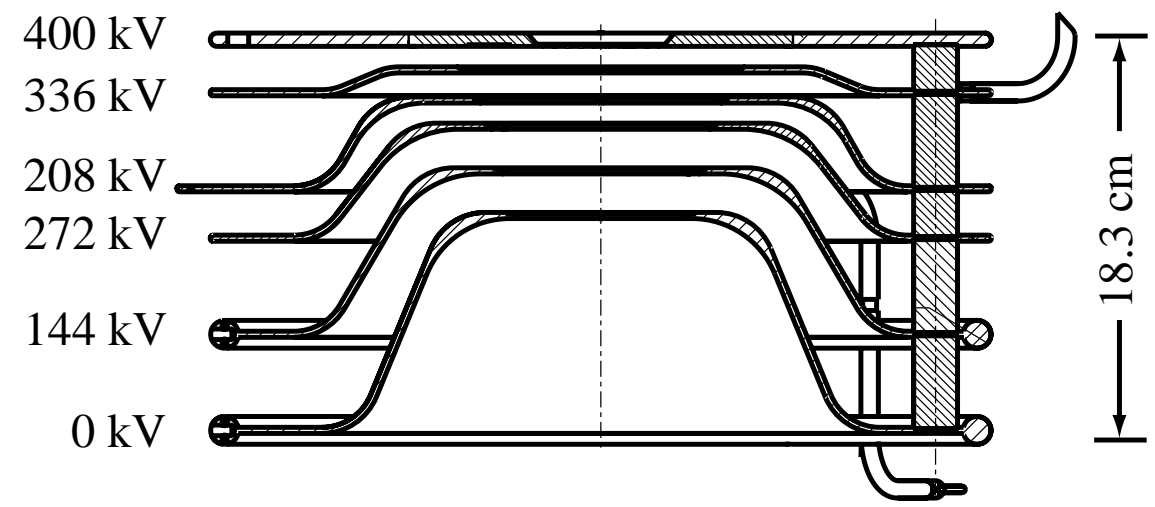

Fig. 6. Layout of the plates in the Full-Gradient Experiment. 


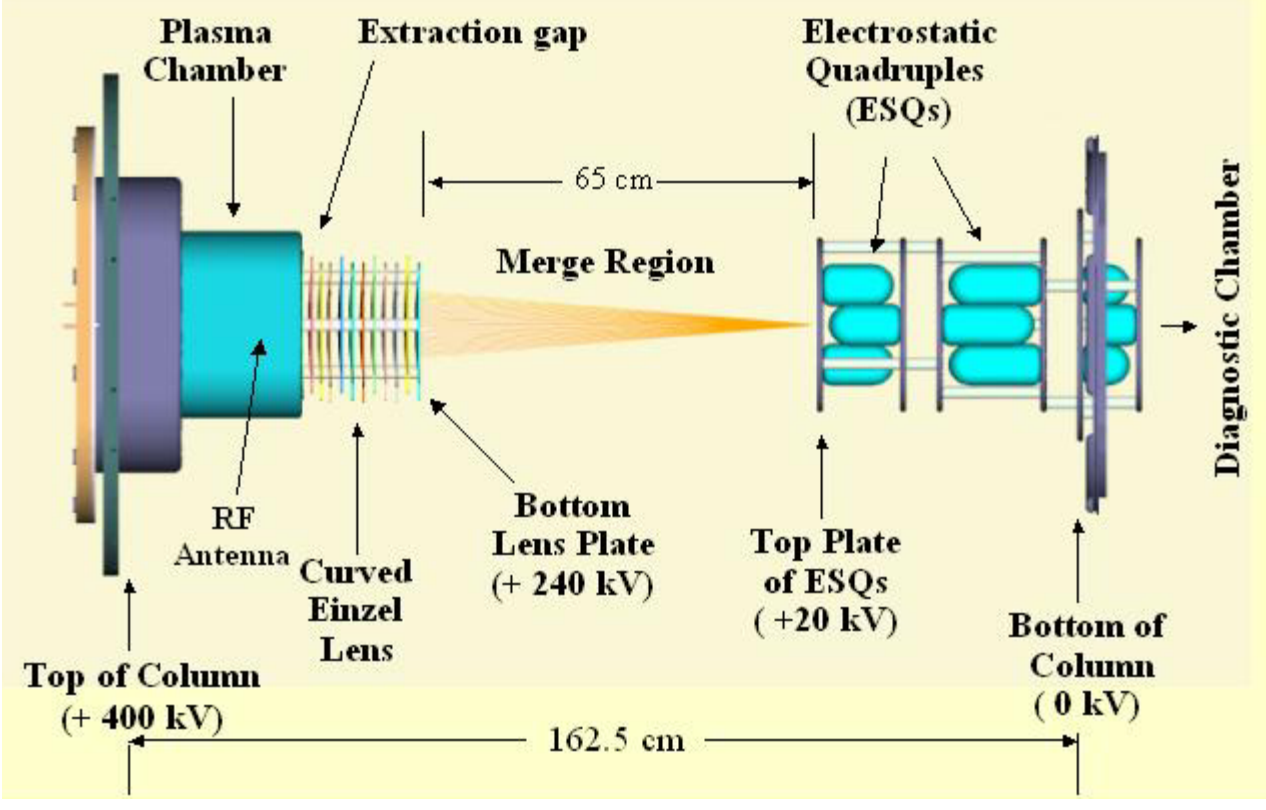

Fig. 7. Layout of the Merge Experiment.

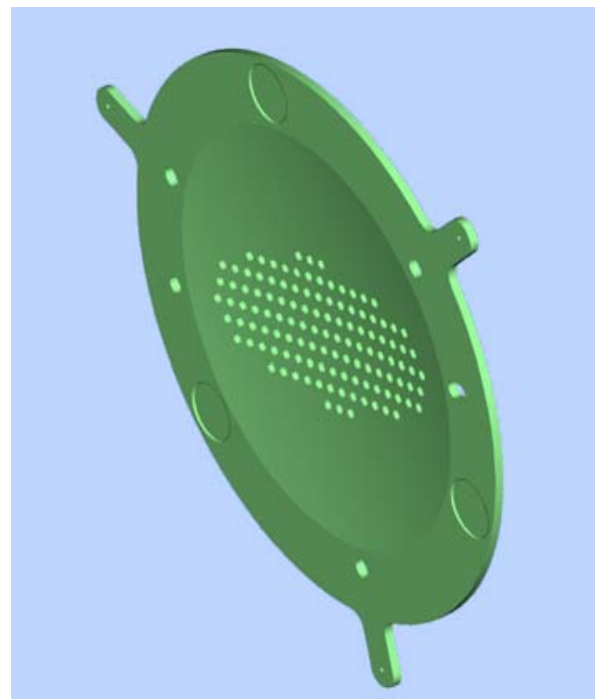

Fig. 8. One of the lens plates used in the assemble. The curvature of the plate is about $60 \mathrm{~cm}$. There are 119 holes for the beamlets, with about $6 \mathrm{~mm}$ between holes. The plate's outer diameter is $20 \mathrm{~cm}$. The plates of Stainless Steel. 


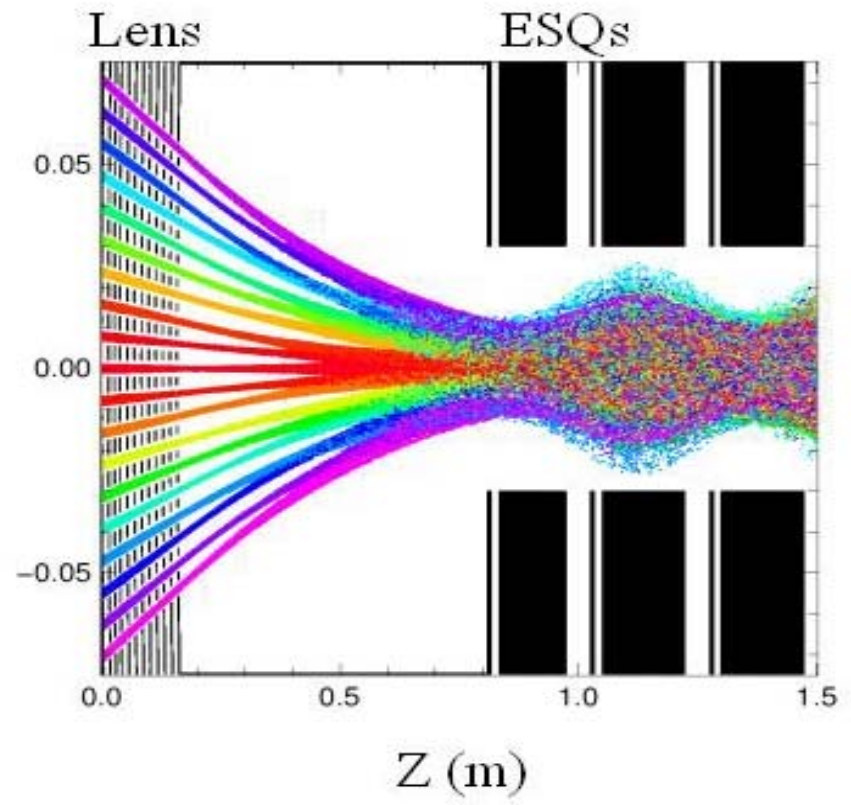

Fig. 9. Simulation showing mixing of the beamlets in the Merge and ESQs Regions. View is from the top of previous figure. 